\title{
Disparity in Health-Related Quality of Life Between Kidney Transplant Recipients and Hemodialysis Patients, and Related Implications for Physical Rehabilitation: A Cross-Sectional Study
}

\author{
Adnan L Sarhan \\ An-najah National University Faculty of Medicine and Health Sciences \\ Raya H Jarareh \\ Palestine Medical Complex \\ Mujahed Shraim ( $\nabla$ mshraim@qu.edu.qa ) \\ Qatar University https://orcid.org/0000-0001-7972-8210
}

\section{Research}

Keywords: Health-related quality of life, Physical Functioning, Hemodialysis, Kidney Transplantation, Cross-sectional study

Posted Date: January 13th, 2021

DOl: https://doi.org/10.21203/rs.3.rs-142930/v1

License: (a) (1) This work is licensed under a Creative Commons Attribution 4.0 International License.

Read Full License 


\section{Abstract}

Background: Health related quality of life (HRQOL) is an important indicator of medical treatment and is a strong predictor of disability and mortality. The literature has shown mixed evidence about whether kidney transplantation improves HRQOL compared with other renal replacement modalities. The aim of this study was to compare the HRQOL in kidney transplant recipients (KTRs) and hemodialysis (HD) patients.

Methods: A cross-sectional study of 100 KTRs and 272 HD patients from two central kidney units in West Bank, Palestine. The HRQOL was assessed using the Short Form-36 Health Survey. Multivariable linear regression was used to estimate differences in mean HRQOL scores between KTRs and HD patients.

Results: After accounting for sociodemographic variables, KTRs had higher clinically important differences than HD patients in HRQOL mean scores in role-physical, bodily pain, general health, vitality, social functioning, role-emotional, mental health, physical and mental component summaries ranging from 15.5 points for social functioning $(95 \% \mathrm{Cl} 10.1,20.7)$ to 34.3 points for general health $(95 \% \mathrm{Cl} 28.7$, 39.9). However, unexpectedly, KTRs had significantly lower HRQOL physical functioning than HD patients by 24.5 points $(95 \% \mathrm{Cl} 18.7,29.9)$.

Conclusions: Kidney transplantation is associated with important improvements in most aspects of HRQOL but also with noticeably poor physical functioning. HRQOL among KTRs should be routinely measured and closely monitored in clinical settings. KTRs should be encouraged to participate in individually tailored physical exercise programs. Identification and elimination of barriers to physical functioning may improve HRQOL and prevent premature mortality among KTRs.

\section{Background}

Chronic kidney disease is a growing global burden in terms of mortality, disability, and financial costs to the community $(1,2)$. Recent estimates suggest that around $13 \%$ of the general population worldwide have some form of chronic kidney disease (3). According to the systematic analysis of the Global Burden of Disease Study 2016, around 1.2 million deaths and 35 million disability-adjusted life years in 2016 were attributed to chronic kidney disease, which represents an increase in mortality and disability by $98 \%$ and $62 \%$ since 1990 , respectively (4). A significant proportion of patients with chronic kidney disease progress to end stage renal disease $(5,6)$. Renal dialysis and kidney transplantation are the only two types of treatment currently available for patients with end stage renal disease (7). Globally, around 2.6 million patients received dialysis in 2010 , and this number is projected to raise to 4.9 million by 2030 (8). Recent estimates show that around 90,000 kidney transplants were performed globally in 2016, which reflects an increase of $18 \%$ since 2015 (9). The literature suggests that kidney transplantation improves survival rates among patients on renal replacement therapy $(10,11)$. However, kidney transplantation requires long-term immunosuppressive therapy, which is associated with significant side effects that affect patient's health-related quality of life (HRQOL) negatively, such as recurrent infection, 
metabolic disorder, renal toxicity, fatigue, and poor self-perception of physical appearance (12-14). HRQOL is a significant independent predictor of hospitalization and mortality in patients on renal replacement therapy $(15,16)$. HRQOL remains is an important health outcome measure in kidney transplant recipients and in dialysis patients, which help clinicians and patients make rational decisions about the optimal choice of treatment modality. The current literature shows mixed findings on whether kidney transplantation is associated with clinically important improvement in HRQOL in kidney transplant recipients as compared with kidney dialysis patients $(17,18)$. In addition, clinically relevant HRQOL could be influenced by disease severity and comorbidities, socioeconomic status, cultural background, religion, environment, and other various factors (19). Research examining HRQOL among kidney transplant recipients (KTRs) and hemodialysis (HD) patients in the Middle East is sparse. The aim of this study was to compare the HRQOL in KTRs and HD patients in West Bank, Palestine.

\section{Methods}

\section{Study design}

We conducted a cross-sectional study among KTRs and HD patients.

\section{Setting and patient recruitment}

The study was conducted in two of the twelfth kidney dialysis units in West Bank between May and August 2017. The first unit is located at Palestine Medical Complex in Ramallah city and the second unit is located at An-Najah National University Hospital in Nablus city. The total number of kidney dialysis patients in these two units $(n=451)$ represented about $37 \%$ of all kidney dialysis patients $(n=1216)$ in West Bank in 2017 (20). HD patients were eligible to participate in the study if they were aged 18 years or over and were on HD for at least three months at recruitment. KTRs were eligible to participate in the study if they were aged 18 years or older and had functioning kidney transplant for at least on year at recruitment. All eligible patients were invited to participate in the study while attending their scheduled HD sessions or follow-up appointments at nephrology clinics during the study period. One of the researchers (RJ) met all eligible patients and invited them to participate in the study after explaining the purpose of the study and the nature of participation. All patients who signed written informed consents were then interviewed by the same researcher and completed a self-reported questionnaire in Arabic. The questionnaire collected data on sociodemographic variables and HRQOL.

\section{Sociodemographic variables}

In addition to renal replacement therapy type (kidney transplantation or HD), we collected data on age (18-29, 30-60, and $>60$ years), gender (female, male), education level (elementary, primary, secondary, and $>$ secondary education), and residential area (city, village, and refugee camp) of participants.

\section{Assessment of HRQOL}


We assessed participants' perceived HRQOL using the 36-Item Short Form Health Survey (SF-36) (21). The SF-36 self-report survey is a widely used instrument to assess the perceived HRQOL, which has been validated in several languages including Arabic $(22,23)$ and in patients with different health conditions including HD and kidney transplantation (24-26). The SF-36 assesses different domains of HRQOL using eight subscales (physical functioning, role-physical, bodily pain, general health, vitality, social functioning, role-emotional, and mental health) and two component summary measures are derived from the eight subscales (physical component summary (PCS) and mental component summary (MCS)). The PCS represents a summary of physical functioning, role-physical, bodily pain, and general health, where the MCS represents a summary of vitality, social functioning, role-emotional and mental health subscales. The number of questions pertaining to each subscale range from two for bodily pain and social functioning to ten for physical functioning, and the number of responses to each question ranges from two options (yes, no) to six-point Likert scale (none, very mild, mild, moderate, severe, and very severe). Each response option is numerically coded and then converted into a score of 0 to 100 . A mean score for each subscale and the two component summary measures is computed, with higher mean scores indicating better perceived HRQOL (21).

\section{Statistical analysis}

We used frequencies with percentages to summarize the sociodemographic variables. We used chisquare tests to examine for any statistically significant differences between the KTRs and HD patients in sociodemographic characteristics. The renal replacement therapy type (Kidney transplantation and hemodialysis) and sociodemographic characteristics were modeled as predictors of mean scores of SF36 subscales, PCS, and MCS. We used multivariable linear regression to assess the relationship between sociodemographic variables with PCS and MCS scores among KTRs and HD patients separately. Similarly, we used multivariable linear regression to assess differences in HRQOL scores between KTRs and HD patients after adjusting for sociodemographic characteristics. The HRQOL scores for all subdomains, PCS and MCS were not normally distributed. Therefore, we used bootstrap sampling and estimation method, with 1000 repetitions, in all regression analyses. All inferential statistical tests were two-sided. A $P$-value less than 0.05 was considered statistically significant. All analyses were performed using IBM SPSS Statistics computer program (version 26.0, IBM Corp).

\section{Results}

Three hundred and seventy-two patients participated in the study (100 KTRs (26.9\%) and 272 HD patients (73.1\%)). The sociodemographic characteristics of participants are summarized in Table 1. The sociodemographic characteristics differed significantly between the two groups for all variables except for residential area (city, village, or refugee camp). The KTRs were younger than HD patients; $36 \%$ of KTRs aged $18-29$ years as compared to $6.3 \%$ HD patients. About $75 \%$ and $58.1 \%$ of KTRs and HD patients were men, respectively. Additionally, higher proportion of KTRs (72\%) obtained secondary school education or higher than HD patients (39.3\%). 


\section{Unadjusted differences in perceived HRQOL scores between KTRs and HD patients}

As shown in Fig. 1, KTRs had significantly higher HRQOL scores in all SF-36 subscales (except physical functioning), PCS, and MCS than the HD patients. The higher HRQOL scores among KTRs than HD patients ranged from 22.9 points for social functioning to 46.8 points for role-physical. Surprisingly, KTRs had significantly lower mean physical functioning score than HD patients by 41.8 points. Distributions of physical functioning scores among KTRs and HD are shown in Fig. 2.

Table 1

Sociodemographic characteristics of kidney transplant recipients and hemodialysis patients

\begin{tabular}{|c|c|c|c|}
\hline Variable & $\begin{array}{l}\text { Kidney transplant recipients }(n=100) \\
\text { Frequency }(\%)\end{array}$ & $\begin{array}{l}\text { Hemodialysis patients }(n=272) \\
\text { Frequency }(\%)\end{array}$ & $p$-value \\
\hline \multirow{2}{*}{$\begin{array}{l}\text { Age group } \\
\text { (years) }\end{array}$} & $36(36.0)$ & $17(6.3)$ & \multirow[t]{5}{*}{$<0.001$} \\
\hline & $61(61.0)$ & 151 (55.5) & \\
\hline $10<3$ & \multirow[t]{3}{*}{$3(3.0)$} & \multirow[t]{3}{*}{104 (38.2) } & \\
\hline $30-60$ & & & \\
\hline$>60$ & & & \\
\hline Gender & $25(25.0)$ & $114(41.9)$ & 0.002 \\
\hline Female & 75 (75.0) & $158(58.1)$ & \\
\hline \multicolumn{4}{|l|}{ Male } \\
\hline \multirow{2}{*}{$\begin{array}{l}\text { Education } \\
\text { level }\end{array}$} & $23(23.0)$ & $52(19.1)$ & \multirow[t]{4}{*}{$<0.001$} \\
\hline & $5(5.0)$ & $113(41.5)$ & \\
\hline Elementary & $40(40.0)$ & 48 (17.6) & \\
\hline $\begin{array}{l}\text { Primary } \\
\text { school }\end{array}$ & $32(32)$ & 59 (21.7) & \\
\hline \multicolumn{4}{|l|}{$\begin{array}{l}\text { Secondary } \\
\text { school }\end{array}$} \\
\hline \multicolumn{4}{|l|}{$>$ Secondary } \\
\hline \multirow{2}{*}{$\begin{array}{l}\text { Residential } \\
\text { area }\end{array}$} & $33(33.0)$ & $76(27.9)$ & \multirow[t]{5}{*}{0.166} \\
\hline & $58(58.0)$ & $151(55.5)$ & \\
\hline city & $9(9.0)$ & 45 (16.5) & \\
\hline . & & & \\
\hline $\begin{array}{l}\text { Refugee } \\
\text { camp }\end{array}$ & & & \\
\hline
\end{tabular}




\section{Sociodemographic factors associated with perceived HRQOL scores among KTRs and HD patients}

The detailed associations between sociodemographic variables and HRQOL scores at SF-36 subscale level are not the focus of the current study. Therefore, we report here only the adjusted associations between sociodemographic variables with PCS and MCS scores in KTRs and HD patients (detailed data on associations between the sociodemographic variables and HRQOL scores at SF-36 subscale level are available from the authors upon reasonable request). As shown in Table 2, KTRs aged 18-29 years had lower MCS score by 7.3 points than KTRs aged 30-60 years ( $95 \% \mathrm{Cl} 1.8,12.9)$. However, HD patients aged $18-29$ had higher MCS score than HD patients aged $30-60$ by 11.5 points $(95 \% \mathrm{Cl} 1.2,22.0)$. There were no other statistically significant differences between other age groups in MCS or PCS scores in KTRs or HD patients (Table 2). Higher education level was associated with higher PCS and MCS scores among KTRs and HD patients. KTRs with education level higher than secondary school had increased PCS and MCS scores by $8.8(95 \% \mathrm{Cl} 2.5,16.0)$ and 11.0 points $(95 \% \mathrm{Cl} 2.5,18.7)$ than KTRs with primary school education level, respectively. Similarly, HD patients with education level higher than secondary school had higher PCS and MCS scores by 10.4 (95\% Cl 5.6, 15.1) and 18 points $(95 \% \mathrm{Cl} 8.4,26.4)$ than HD patients with elementary school education level, respectively. 
Table 2

Sociodemographic factors associated with physical and mental component summary scores in kidney transplant recipients and hemodialysis patients

\begin{tabular}{|c|c|c|c|c|c|c|c|c|}
\hline \multirow[t]{3}{*}{ Predictor } & \multicolumn{4}{|c|}{ Kidney transplant recipients $(n=100)$} & \multicolumn{4}{|c|}{ Hemodialysis patients $(n=272)$} \\
\hline & \multicolumn{2}{|l|}{ PCS } & \multicolumn{2}{|l|}{ MCS } & \multicolumn{2}{|l|}{ PCS } & \multicolumn{2}{|l|}{ MCS } \\
\hline & $\begin{array}{l}\beta(\mathrm{BCa} \\
95 \% \mathrm{Cl})\end{array}$ & $\begin{array}{l}\mathrm{p}- \\
\text { value }\end{array}$ & $\begin{array}{l}\beta(\mathrm{BCa} \\
95 \% \mathrm{Cl})\end{array}$ & $\begin{array}{l}\text { p- } \\
\text { value }\end{array}$ & $\begin{array}{l}\beta(\mathrm{BCa} \\
95 \% \mathrm{Cl})\end{array}$ & $\begin{array}{l}\mathrm{p}- \\
\text { value }\end{array}$ & $\begin{array}{l}\beta(\mathrm{BCa} \\
95 \% \mathrm{Cl})\end{array}$ & $\begin{array}{l}\text { p- } \\
\text { value }\end{array}$ \\
\hline Age group & Ref & 0.069 & Ref & 0.020 & Ref & 0.741 & -3.6 & 0.515 \\
\hline $18-29$ & $\begin{array}{l}4.6(0.0 \\
9.7)\end{array}$ & 0.265 & $\begin{array}{l}7.3(1.8 \\
12.9)\end{array}$ & 0.074 & $\begin{array}{l}1.0(-4.9 \\
6.3)\end{array}$ & 0.448 & $\begin{array}{l}(-13.9, \\
6.8)\end{array}$ & 0.039 \\
\hline $\begin{array}{l}30-60 \\
>60\end{array}$ & $\begin{array}{l}-3.4(-9.4 \\
3.6)\end{array}$ & & $\begin{array}{l}-9.6(-22.2 \\
1.7)\end{array}$ & & $\begin{array}{l}-2.3(-8.7 \\
3.6)\end{array}$ & & $\begin{array}{l}-1.5 \\
(-22.0 \\
-1.2)\end{array}$ & \\
\hline & Ref & 0.410 & Ref & 0.966 & Ref & 0.343 & $\begin{array}{l}5.7(0.3 \\
112)\end{array}$ & 0.055 \\
\hline $\begin{array}{l}\text { Female } \\
\text { Male }\end{array}$ & $\begin{array}{l}-2.1(-7.1, \\
4.5)\end{array}$ & & $\begin{array}{l}0.1(-7.4 \\
8.4)\end{array}$ & & $\begin{array}{l}1.5 \\
(-1.7,4.5)\end{array}$ & & & \\
\hline $\begin{array}{l}\text { Education } \\
\text { level }\end{array}$ & $\begin{array}{l}-3.8 \\
(-15.7 \\
5.6)\end{array}$ & $\begin{array}{l}0.456 \\
0.004\end{array}$ & $\begin{array}{l}-11.4 \\
(-37.5 \\
9.0)\end{array}$ & $\begin{array}{l}0.274 \\
0.002\end{array}$ & $\begin{array}{l}-10.4 \\
(-15.1 \\
-5.6)\end{array}$ & $\begin{array}{l}0.001 \\
0.072\end{array}$ & $\begin{array}{l}-18.0 \\
(-26.4 \\
-8.4)\end{array}$ & $\begin{array}{l}0.001 \\
0.009\end{array}$ \\
\hline $\begin{array}{l}\text { Primary } \\
\text { school }\end{array}$ & $\begin{array}{l}-8.8 \\
(-16.0 \\
-2.5)\end{array}$ & 0.064 & $\begin{array}{l}-11.0 \\
(-18.7 \\
-2.5)\end{array}$ & 0.173 & $\begin{array}{l}-4.7(-10.2 \\
0.4)\end{array}$ & 0.077 & $\begin{array}{l}-11.6 \\
(-20.7 \\
-1.9)\end{array}$ & 0.145 \\
\hline $\begin{array}{l}\text { Secondary } \\
\text { school }\end{array}$ & $\begin{array}{l}-4.8(-9.5 \\
0.6)\end{array}$ & & $\begin{array}{l}-5.1(-12.3, \\
2.8)\end{array}$ & & $0.5)$ & & $\begin{array}{l}-7.0 \\
(-16.6\end{array}$ & \\
\hline$>$ Secondary & Ref & & & & & & & \\
\hline $\begin{array}{l}\text { Residential } \\
\text { area }\end{array}$ & Ref & 0.925 & Ref & 0.966 & Ref & 0.089 & $\begin{array}{l}6.5(-1.2, \\
138)\end{array}$ & 0.088 \\
\hline City & $\begin{array}{l}0.2(-4.7 \\
5.1)\end{array}$ & 0.458 & $\begin{array}{l}-6.1(-23.3, \\
8.9)\end{array}$ & 0.612 & $\begin{array}{l}3.4(-0.5 \\
7.5)\end{array}$ & 0.663 & $\begin{array}{l}1.4(-8.5 \\
11.2)\end{array}$ & 0.774 \\
\hline $\begin{array}{l}\text { Village } \\
\text { Refugee } \\
\text { camp }\end{array}$ & $\begin{array}{l}-3.8 \\
(-14.3 \\
5.8)\end{array}$ & & $\begin{array}{l}1.8(-5.2 \\
9.1)\end{array}$ & & $\begin{array}{l}1.1(-4.2 \\
7.1)\end{array}$ & & & \\
\hline
\end{tabular}

In addition, HD patients with higher than secondary school education level had increased MCS score by 11.6 points than HD patients with primary education level $(95 \% \mathrm{Cl} 1.9,20.7)$. We found no statistically significant differences in PCS or MCS scores according to gender or residential area among either KTRs or HD patients (Table 2). 


\section{Adjusted differences in perceived HRQOL scores between KTRs and HD patients}

After adjustment for sociodemographic variables (age group, gender, education level, and residential area), KTRs had significantly higher clinically important differences in all SF-36 subscales (except for physical functioning) ranging between 15.5 points for social functioning $(95 \% \mathrm{Cl} 10.1,20.7)$ and 34.3 points for general health $(95 \% \mathrm{Cl} 28.7,39.9)$. However, KTRs had significantly lower physical functioning score by 24.5 points $(95 \% \mathrm{Cl} 18.7,29.9)$ than HD patients (Table 3$)$.

\section{Discussion}

The aim of this study was to compare the perceived HRQOL in KTRs and HD patients. The current study has shown that KTRs were more likely to be younger, men, and with higher education level than HD patients. Younger KRTs had significantly lower MCS score than older KTRs. Conversely, younger HD patients had significantly higher MCS score than older HD patients. There were no significant differences in PCS scores by age group in either KTRs or HD patients. After controlling for sociodemographic variables, we found clinically significant differences in perceived HRQOL between KTRs and HD patients. KTRs had significantly higher perceived HRQOL scores in role-physical, bodily pain, general health, vitality, social functioning, role-emotional, mental health, physical component summary, and mental component summary than HD patients. These observed differences ranged between 15.5 points in social functioning and 34.3 points in general health. However, contrary to our expectations, KTRs had significantly lower perceived HRQOL in physical functioning than HD patients by 25 points. The magnitude of observed differences in HRQOL scores between KTRs and HD patients in the current study are considered clinically important differences based on the cut-off points for the minimal clinically important difference (3-5 points) for any health condition (27), 6-11 points for patients with stage five chronic kidney disease (28), and 15 points for patients with heart disease (29). Our observed differences between KTRs and HD patients in age, gender, and education level are consistent with those of other studies and suggest that KRTs are more likely to be younger, men, and have higher education level $(30,31)$. 
Table 3

Adjusted differences in perceived HRQOL scores between kidney transplant recipients $(n=100)$ and hemodialysis patients $(\mathrm{n}=272)$

\begin{tabular}{|c|c|c|c|c|c|c|}
\hline SF-36 dimensions & Group & $\begin{array}{l}\beta(B C a 95 \% \\
C l)^{a}\end{array}$ & S.E. & $\begin{array}{l}\text { Mean score } \\
(95 \% \mathrm{Cl})\end{array}$ & $\begin{array}{l}\text { S.E. of } \\
\text { mean }\end{array}$ & $\begin{array}{l}p \\
\text { value }\end{array}$ \\
\hline \multirow[t]{2}{*}{ Physical functioning } & KTRs & $\begin{array}{l}-24.5(-29.9, \\
-18.7)\end{array}$ & \multirow[t]{2}{*}{3.0} & $\begin{array}{l}27.9(22.4 \\
33.3)\end{array}$ & \multirow{2}{*}{$\begin{array}{l}2.8 \\
1.9\end{array}$} & \multirow[t]{2}{*}{0.001} \\
\hline & HDPs & Ref & & $\begin{array}{l}52.3(48.6 \\
56.1)\end{array}$ & & \\
\hline \multirow[t]{2}{*}{ Role-physical } & \multirow{2}{*}{$\begin{array}{l}\text { KTRs } \\
\text { HDPs }\end{array}$} & $\begin{array}{l}32.6(24.0, \\
41.1)\end{array}$ & \multirow{2}{*}{$\begin{array}{l}4.4 \\
-\end{array}$} & $\begin{array}{l}67.8(59.8, \\
75.7)\end{array}$ & \multirow{2}{*}{$\begin{array}{l}2.8 \\
1.9\end{array}$} & \multirow[t]{2}{*}{0.001} \\
\hline & & Ref & & $\begin{array}{l}35.2(29.7 \\
40.6)\end{array}$ & & \\
\hline \multirow[t]{2}{*}{ Bodily pain } & KTRs & $\begin{array}{l}24.8(18.2, \\
31.4)\end{array}$ & \multirow{2}{*}{$\begin{array}{l}3.3 \\
-\end{array}$} & $\begin{array}{l}79.6(73.6, \\
85.5)\end{array}$ & \multirow{2}{*}{$\begin{array}{l}2.1 \\
3.0\end{array}$} & \multirow[t]{2}{*}{0.001} \\
\hline & HDPs & Ref & & $\begin{array}{l}54.7(50.7 \\
58.8)\end{array}$ & & \\
\hline \multirow[t]{2}{*}{ General health } & & $\begin{array}{l}34.3(28.7 \\
39.9)\end{array}$ & \multirow[t]{2}{*}{2.7} & $\begin{array}{l}57.1 \text { (70.3, } \\
79.9)\end{array}$ & & \multirow[t]{2}{*}{0.00} \\
\hline & HDPs & Ref & & $\begin{array}{l}40.8(37.5, \\
44.2)\end{array}$ & 1.7 & \\
\hline \multirow[t]{2}{*}{$\begin{array}{l}\text { Physical component } \\
\text { summary }\end{array}$} & KTRs & $\begin{array}{l}16.8(13.8, \\
19.9)\end{array}$ & \multirow{2}{*}{$\begin{array}{l}1.5 \\
-\end{array}$} & $\begin{array}{l}62.6(59.8, \\
65.4)\end{array}$ & 1.4 & \multirow[t]{2}{*}{0.00} \\
\hline & HDPs & Ref & & $\begin{array}{l}45.8(43.9, \\
47.9)\end{array}$ & 1.0 & \\
\hline \multirow[t]{2}{*}{ Vitality } & KTRs & $\begin{array}{l}20.5(14.9 \\
26.6)\end{array}$ & \multirow{2}{*}{$\begin{array}{l}3.1 \\
-\end{array}$} & $\begin{array}{l}59.8(54.6, \\
64.9)\end{array}$ & 2.6 & \multirow[t]{2}{*}{0.001} \\
\hline & HDPs & Ref & & $\begin{array}{l}39.3(35.8, \\
42.9)\end{array}$ & 1.8 & \\
\hline \multirow[t]{2}{*}{ Social functioning } & & $\begin{array}{l}15.5(10.1 \\
20.7)\end{array}$ & \multirow[t]{2}{*}{2.6} & $\begin{array}{l}87.9(82.2, \\
93.5)\end{array}$ & 2.9 & \multirow[t]{2}{*}{0.001} \\
\hline & HDPs & Ref & & $\begin{array}{l}72.4(68.5, \\
76.3)\end{array}$ & 2.0 & \\
\hline
\end{tabular}

KTRs Kidney transplant recipients, HDPs Hemodialysis patients, SE Standard error, BCa Bias corrected accelerated, $\mathrm{Cl}$ Confidence interval, Ref Reference category.

aSF-36 HRQOL subscales and physical and mental component summary score estimates are adjusted for age group, gender, education level, and residential area. 


\begin{tabular}{|c|c|c|c|c|c|c|}
\hline SF-36 dimensions & Group & $\begin{array}{l}\beta(B C a 95 \% \\
C l)^{a}\end{array}$ & S.E. & $\begin{array}{l}\text { Mean score } \\
(95 \% \mathrm{Cl})\end{array}$ & $\begin{array}{l}\text { S.E. of } \\
\text { mean }\end{array}$ & $\begin{array}{l}p \\
\text { value }\end{array}$ \\
\hline \multirow[t]{2}{*}{ Role-emotional } & KTRs & $\begin{array}{l}29.5(20.2 \\
39.7)\end{array}$ & \multirow{2}{*}{$\begin{array}{l}4.8 \\
-\end{array}$} & $\begin{array}{l}68.6(59.8, \\
77.3)\end{array}$ & 4.5 & \multirow[t]{2}{*}{0.001} \\
\hline & HDPs & Ref & & $\begin{array}{l}39.0(33.0 \\
45.1)\end{array}$ & 3.1 & \\
\hline \multirow[t]{2}{*}{ Mental health } & & $\begin{array}{l}24.5(17.5 \\
30.6)\end{array}$ & \multirow[t]{2}{*}{3.2} & $\begin{array}{l}73.7(67.5, \\
79.8)\end{array}$ & & \multirow[t]{2}{*}{0.001} \\
\hline & HDPs & Ref & & $\begin{array}{l}49.2(45.0, \\
53.4)\end{array}$ & 2.2 & \\
\hline \multirow[t]{2}{*}{$\begin{array}{l}\text { Mental component } \\
\text { summary }\end{array}$} & KTRs & $\begin{array}{l}22.5(17.6, \\
27.5)\end{array}$ & \multirow{2}{*}{$\begin{array}{l}2.6 \\
-\end{array}$} & $\begin{array}{l}72.5(67.7, \\
773)\end{array}$ & \multirow{2}{*}{$\begin{array}{l}2.5 \\
1.7\end{array}$} & \multirow[t]{2}{*}{0.001} \\
\hline & HDPs & Ref & & $\begin{array}{l}50.0(46.7 \\
53.3)\end{array}$ & & \\
\hline \multicolumn{7}{|c|}{$\begin{array}{l}\text { KTRs Kidney transplant recipients, HDPs Hemodialysis patients, SE Standard error, } B C a \text { Bias corrected } \\
\text { accelerated, } \mathrm{Cl} \text { Confidence interval, Ref Reference category. }\end{array}$} \\
\hline
\end{tabular}

One explanation of the observed higher proportion of younger individuals among KTRs than HD patients is that younger patients with end stage kidney disease are less likely to have comorbid conditions than older patients, which makes younger patients better candidates for kidney transplantation (32). Our finding of high proportion of men than women among KTRs and HD patients could be explained by the higher prevalence of non-communicable disease risk factors and the faster progression of end stage kidney disease in men more than women $(33,34)$. A plausible explanation for our finding of higher education level (a proxy measure for socioeconomic) among KTRs than HD patients is that socioeconomic status advantaged patients may have higher expectations for health and preference for kidney transplantation (35). Additionally, individuals with higher socioeconomic status are more likely to have lower prevalence of comorbid conditions and other contraindications for kidney transplantation, such as smoking and obesity (36). This explanation also applies to our finding of higher physical and mental health summary scores among KTRs and HD patients. The lower mental health summary score among younger KTRs found in the current study could be explained by their potential higher levels of worry about allograft survival, employment, and other economic factors $(37,38)$.

The findings of our study are consistent with the findings of previous studies suggesting that kidney transplantation is associated with better physical and mental HRQOL scores than other renal replacement therapies $(25,39,40)$. In contrast to these findings, however, a systematic review with meta-regression, found no clinically meaningful differences between KTRs and HD patients in four dimensions of HRQOL (role physical, bodily pain, vitality, and mental health) after adjusting for age and diabetes. However, the findings of meta-regression analyses should be interpreted with caution because any observed 
differences aggregated across studies may not necessarily apply to individual patients within single studies (ecological fallacy). The explanations for the contradictory findings between our study and the aforementioned systematic review are largely unclear. One plausible explanation is that long-term use of immunosuppression medications by KTRs is commonly associated with important side effects, such as significant weight gain, recurrent infection, diabetes, hypertension, cardiovascular disease, and poor selfperception of physical appearance $(13,14)$. For example, a cohort study of nondiabetic KTRs $(n=25,837)$ found that $17.7 \%$ and $12.3 \%$ of KTRs who were prescribed steroid-containing and steroid-free immunosuppressive regimens developed new onset of diabetes within three years post transplantation, respectively (41). This suggests that initial improvements in some aspects of HRQOL among KTRs may decline over time. This plausible explanation is supported by the findings of previous cohort studies examining HRQOL among KTRs $(17,37,42)$. For instance, a five-year prospective cohort study of 110 KTRs and HD patients found no clinically important differences between KTRs and HD patients in five dimensions of HRQOL (physical functioning, bodily pain, role-emotional, mental health, and MCS scores) by the end of follow up (42).

The present study found that KTRs had lower perceived HRQOL in physical functioning by 25 points than HD patients, which is a novel finding that, to our knowledge, has not previously been described. The exact mechanisms underlying this finding are not very clear. This is because physical functioning is determined by several factors including physical activity, physical fitness level, and other known barriers to physical activity faced by KTRs, such as fear of physical activity and allograft rejection, immunosuppression side effects, new-onset of medical comorbidities, obesity, socioeconomic factors, and inadequate self-care strategies and clinician guidance on physical exercise $(43,44)$. One potential explanation for our finding is that determinants and barriers of physical functioning might be more prevalent, or have greater negative impact, among KTRs in our sample as compared to other KTRs in other regions, which needs to be further explored. For example, one recent study showed that about $46 \%$ of KTRs in Palestine were unemployed (30), whereas only $6 \%$ of German KTRs were reported to be unemployed (40). Another potential explanation is that perceived HRQOL measures do not account for individual variations in expectations and actual experiences of healthcare outcomes, which may be driven by diverse factors, such as culture, spirituality, socioeconomic status, personality, and other sociodemographic factors (45). This explanation suggests that KTRs may under report their HRQOL if their high expectations for health and recovery are not met completely. However, we think that this explanation is not plausible because we would expect KTRs to under report their HRQOL in other subscales of physical and mental health subscales as well, which we did not observe. Therefore, we think that the observed lower HRQOL in physical functioning score among KTRs compared with HD patients is highly likely to be explained by the aforementioned barriers to physical functioning among KTRs and inadequate vocational and physical rehabilitation after kidney transplantation $(40,44)$. For example, a qualitative study among KTRs showed that about $80 \%$ and $40 \%$ of KTRs reported having a sedentary lifestyle and receiving little clinical guidance on physical exercise after transplantation, respectively (44).

The present study included a relatively large number of KTRs and HD patients from two kidney units representing $37 \%$ of patients on renal replacement therapy in the West Bank (20). The sociodemographic 
characteristics of participants in our study are very similar to those of other studies from Palestine and other regions $(30,31)$. In addition, we accounted for key predictors of HRQOL using multivariable regression analysis. Additionally, the Palestinian population is highly homogeneous in terms of ethnicity, culture, spirituality, and physical environment. This enhances the validity of our study, and therefore our findings are highly likely to be generalizable to KTRs and HD patients in Palestine. However, our findings may not generalize to other populations and regions with different healthcare system, culture, religious beliefs, ethnicity, and other socioeconomic factors influencing HRQOL.

Several limitations need to be noted regarding the present study. First, we used a cross-sectional design to address the aim of the study, and therefore, the temporality and direction of observed differences in perceived HRQOL scores between KTRs and HD patients, presumably attributed to successful kidney transplantation, cannot be established with great confidence. Nonetheless, our findings, taken together, are largely consistent with the findings of other prospective cohort studies $(17,46)$. Second, we collected no information on some factors which adversely affect the HRQOL among patients with end stage renal disease, such as comorbid conditions and biochemical variables, as creatinine (47). However, these factors are more prevalent among HD patients, thus lack of adjustment for those variables is not expected to attenuate the observed clinically important differences in HRQOL values between KRTs and HD patients. Third, self-reported perceived HRQOL is considered a subjective indicator and may be influenced by individual expectations of health and recovery, which may underestimate or overestimate actual healthcare outcomes.

Despite the marked improvements in various aspects of HRQOL attributed to successful kidney transplantation, healthcare professionals managing patients on renal replacement therapy should be aware that KTRs have low perceived HRQOL in physical functioning, which should be addressed and monitored closely. There is some evidence from a systematic review that poor physical capacity among KTRs is associated with poor HRQOL and increased risk of hospital admission rates, length of hospital stay, and mortality (48). For instance, the findings of a cohort study of 10,875 KTRs suggest that a modest improvement in physical functioning may decrease mortality rate by $11 \%$ among KRTs with low levels of physical functioning (49). In addition, a recent systematic review found that exercise therapy for KTRs is associated with significant improvements in HRQOL and exercise tolerance, and may improve renal allograft function (estimated glomerular filtration rate) (48). More recently, the Japanese Society of Renal Rehabilitation has published a guideline recommending exercise therapy for KTRs (50). Therefore, healthcare professionals managing KTRs should encourage KTRs to exercise regularly and give them adequate guidance on participating in exercise training programs tailored to the individual capacity. Multicenter and large longitudinal research studies are needed to better understand determinants of perceived HRQOL and examine potential interventions to enhance the HRQOL among KTRs. In addition, future research on physical and mental health related quality of life among KTRs should include objective measures and account for patients' expectations and experiences of medical treatment outcomes to promote effective communication and shared clinical decision-making. 


\section{Conclusions}

This study adds further evidence that kidney transplantation is associated with improvements in most dimensions of physical and mental HRQOL. Nonetheless, KTRs reported significant worse HRQOL in physical functioning compared with HD patients. Clinicians managing KTRs should be aware of the poor perceived HRQOL in physical functioning among KTRs. Therefore, clinicians need to provide KTRs with adequate guidance on physical exercise and self-care strategies and encourage KTRs to participate in individually tailored physical exercise programs. In addition, HRQOL is an important indicator of healthcare quality and health outcomes in KTRs, which should be routinely measured and closely monitored in clinical settings. More research is needed to identify specific barriers and facilitators to physical functioning among KTRs. This has important implications for future work to minimize or prevent poor HRQOL, disability, and premature mortality among KTRs.

\section{Abbreviations}

Cl: Confidence interval

HD: Hemodialysis

HRQOL: Health related quality of life

KTRs: kidney transplant recipients

MCS: mental component summary

PCS: Physical component summary

SF-36: 36-Item Short Form Health Survey

\section{Declarations}

\section{Ethical approval and consent to participate:}

This study was performed in line with the principles of the Declaration of Helsinki. The study was ethically approved by An-Najah National University Institutional Review Board (Reference number 20/AP/0018). Informed consent was obtained from all individual participants included in the study.

\section{Availability of data and materials:}

The datasets used and/or analysed during the current study are available from the corresponding author on reasonable request. 


\section{Competing interests:}

The authors have no relevant financial or non-financial interests to disclose.

\section{Funding:}

The publication of this article was funded by the Qatar National Library. The funder had no role in study design; collection, analysis, and interpretation of data; writing the report; and the decision to submit the report for publication.

\section{Authors' Contributions:}

All authors contributed to the study conception and design. Material preparation, data collection and analysis were performed by Raya Jarareh, Adnan Sarhan, and Mujahed Shraim. The first draft of the manuscript was written by Adnan Sarhan and all authors commented on previous versions of the manuscript. All authors read and approved the final manuscript.

\section{Acknowledgments:}

We thank the participating patients and the medical staff in kidney units at Palestine Medical Complex and An-Najah National University Hospital for making the study possible.

\section{References}

1. Luyckx VA, Tonelli M, Stanifer JW. The global burden of kidney disease and the sustainable development goals. Bulletin of the World Health Organization. 2018;96(6):414-22D.

2. Couser WG, Remuzzi G, Mendis S, Tonelli M. The contribution of chronic kidney disease to the global burden of major noncommunicable diseases. Kidney Int. 2011;80(12):1258-70.

3. Hill NR, Fatoba ST, Oke JL, Hirst JA, O'Callaghan CA, Lasserson DS, et al. Global Prevalence of Chronic Kidney Disease - A Systematic Review and Meta-Analysis. PLoS One. 2016;11(7):e0158765.

4. Xie Y, Bowe B, Mokdad AH, Xian H, Yan Y, Li T, et al. Analysis of the Global Burden of Disease study highlights the global, regional, and national trends of chronic kidney disease epidemiology from 1990 to 2016. Kidney Int. 2018;94(3):567-81.

5. Dalrymple LS, Katz R, Kestenbaum B, Shlipak MG, Sarnak MJ, Stehman-Breen C, et al. Chronic kidney disease and the risk of end-stage renal disease versus death. J Gen Intern Med. 2011;26(4):379-85.

6. Go AS, Yang J, Tan TC, Cabrera CS, Stefansson BV, Greasley PJ, et al. Contemporary rates and predictors of fast progression of chronic kidney disease in adults with and without diabetes mellitus. BMC nephrology. 2018;19(1):146-. 
7. Abecassis M, Bartlett ST, Collins AJ, Davis CL, Delmonico FL, Friedewald JJ, et al. Kidney transplantation as primary therapy for end-stage renal disease: a National Kidney Foundation/Kidney Disease Outcomes Quality Initiative (NKF/KDOQITM) conference. Clin J Am Soc Nephrol. 2008;3(2):471-80.

8. Liyanage T, Ninomiya T, Jha V, Neal B, Patrice HM, Okpechi I, et al. Worldwide access to treatment for end-stage kidney disease: a systematic review. Lancet. 2015;385(9981):1975-82.

9. Organ donation and transplantation activities 2016 [Internet]. The Global Observatory on Donation and Transplantation. 2018. Available from: http://www.transplant-observatory.org/data-charts-andtables/.

10. Oniscu GC, Brown H, Forsythe JLR. Impact of Cadaveric Renal Transplantation on Survival in Patients Listed for Transplantation. Journal of the American Society of Nephrology. 2005;16(6):1859-65.

11. Kaballo MA, Canney M, O'Kelly P, Williams Y, O'Seaghdha CM, Conlon PJ. A comparative analysis of survival of patients on dialysis and after kidney transplantation. Clin Kidney J. 2018;11(3):389-93.

12. Fiebiger W, Mitterbauer C, Oberbauer R. Health-related quality of life outcomes after kidney transplantation. Health Qual Life Outcomes. 2004;2:2.

13. Gentile S, Beauger D, Speyer E, Jouve E, Dussol B, Jacquelinet C, et al. Factors associated with health-related quality of life in renal transplant recipients: results of a national survey in France. Health Qual Life Outcomes. 2013;11:88.

14. Thiruchelvam PT, Willicombe M, Hakim N, Taube D, Papalois V. Renal transplantation. Bmj. 2011;343:d7300.

15. Mapes DL, Lopes AA, Satayathum S, McCullough KP, Goodkin DA, Locatelli F, et al. Health-related quality of life as a predictor of mortality and hospitalization: the Dialysis Outcomes and Practice Patterns Study (DOPPS). Kidney Int. 2003;64(1):339-49.

16. Lowrie EG, Curtin RB, LePain N, Schatell D. Medical outcomes study short form-36: a consistent and powerful predictor of morbidity and mortality in dialysis patients. Am J Kidney Dis. 2003;41(6):128692.

17. Painter P, Krasnoff JB, Kuskowski M, Frassetto L, Johansen K. Effects of modality change on healthrelated quality of life. Hemodial Int. 2012;16(3):377-86.

18. Liem YS, Bosch JL, Arends LR, Heijenbrok-Kal MH, Hunink MG. Quality of life assessed with the Medical Outcomes Study Short Form 36-Item Health Survey of patients on renal replacement therapy: a systematic review and meta-analysis. Value Health. 2007;10(5):390-7.

19. Crosby RD, Kolotkin RL, Williams GR. Defining clinically meaningful change in health-related quality of life. J Clin Epidemiol. 2003;56(5):395-407.

20. Center. PHI. Health annual report: Palestine 2017. Ramallah: Palestinian Health Information Center; 2018.

21. Ware JE, Jr., Gandek B. Overview of the SF-36 Health Survey and the International Quality of Life Assessment (IQOLA) Project. J Clin Epidemiol. 1998;51(11):903-12. 
22. Sheikh KA, Yagoub U, Elsatouhy M, Al Sanosi R, Mohamud SA. Reliability and Validity of the Arabic Version of the SF-36 Health Survey Questionnaire in Population of Khat Chewers-Jazan RegionKingdom of Saudi Arabia. Applied Research in Quality of Life. 2015;10(1):1-13.

23. Gómez-Besteiro MI, Santiago-Pérez MI, Alonso-Hernández A, Valdés-Cañedo F, Rebollo-Alvarez P. Validity and reliability of the SF-36 questionnaire in patients on the waiting list for a kidney transplant and transplant patients. Am J Nephrol. 2004;24(3):346-51.

24. Leaf DE, Goldfarb DS. Interpretation and review of health-related quality of life data in CKD patients receiving treatment for anemia. Kidney Int. 2009;75(1):15-24.

25. Fujisawa M, Ichikawa Y, Yoshiya K, Isotani S, Higuchi A, Nagano S, et al. Assessment of healthrelated quality of life in renal transplant and hemodialysis patients using the SF-36 health survey. Urology. 2000;56(2):201-6.

26. de Brito DCS, Machado EL, Reis IA, Moreira DP, Nébias THM, Cherchiglia ML. Modality transition on renal replacement therapy and quality of life of patients: a 10-year follow-up cohort study. Qual Life Res. 2019;28(6):1485-95.

27. Samsa G, Edelman D, Rothman ML, Williams GR, Lipscomb J, Matchar D. Determining clinically important differences in health status measures: a general approach with illustration to the Health Utilities Index Mark II. Pharmacoeconomics. 1999;15(2):141-55.

28. Erez G, Selman L, Murtagh FE. Measuring health-related quality of life in patients with conservatively managed stage 5 chronic kidney disease: limitations of the Medical Outcomes Study Short Form 36: SF-36. Qual Life Res. 2016;25(11):2799-809.

29. Wyrwich KW, Spertus JA, Kroenke K, Tierney WM, Babu AN, Wolinsky FD. Clinically important differences in health status for patients with heart disease: an expert consensus panel report. Am Heart J. 2004;147(4):615-22.

30. Dweib K, Jumaa S, Khdour M, Hallak H. Quality of life for kidney transplant palestinian patients. Saudi Journal of Kidney Diseases and Transplantation. 2020;31(2):473-81.

31. Cameron JI, Whiteside C, Katz J, Devins GM. Differences in quality of life across renal replacement therapies: a meta-analytic comparison. Am J Kidney Dis. 2000;35(4):629-37.

32. Huang E, Segev DL, Rabb H. Kidney transplantation in the elderly. Semin Nephrol. 2009;29(6):621-35.

33. Neugarten J, Acharya A, Silbiger SR. Effect of gender on the progression of nondiabetic renal disease: a meta-analysis. J Am Soc Nephrol. 2000;11(2):319-29.

34. Bikbov B, Bieber B, Andrusev A, Tomilina N, Zemchenkov A, Zhao J, et al. Hemodialysis practice patterns in the Russia Dialysis Outcomes and Practice Patterns Study (DOPPS), with international comparisons. Hemodial Int. 2017;21(3):393-408.

35. Moscelli G, Siciliani L, Gutacker N, Cookson R. Socioeconomic inequality of access to healthcare: Does choice explain the gradient? J Health Econ. 2018;57:290-314.

36. Schaeffner ES, Mehta J, Winkelmayer WC. Educational level as a determinant of access to and outcomes after kidney transplantation in the United States. Am J Kidney Dis. 2008;51(5):811-8. 
37. Griva K, Stygall J, Ng JH, Davenport A, Harrison MJ, Newman S. Prospective Changes in HealthRelated Quality of Life and Emotional Outcomes in Kidney Transplantation over 6 Years. J Transplant. 2011;2011:671571.

38. Chisholm MA, Spivey CA, Nus AV. Influence of economic and demographic factors on quality of life in renal transplant recipients. Clin Transplant. 2007;21(2):285-93.

39. Maglakelidze N, Pantsulaia T, Tchokhonelidze I, Managadze L, Chkhotua A. Assessment of healthrelated quality of life in renal transplant recipients and dialysis patients. Transplant Proc. 2011;43(1):376-9.

40. Overbeck I, Bartels M, Decker O, Harms J, Hauss J, Fangmann J. Changes in quality of life after renal transplantation. Transplant Proc. 2005;37(3):1618-21.

41. Luan FL, Steffick DE, Ojo AO. New-onset diabetes mellitus in kidney transplant recipients discharged on steroid-free immunosuppression. Transplantation. 2011;91(3):334-41.

42. von der Lippe N, Waldum B, Brekke FB, Amro AA, Reisæter AV, Os I. From dialysis to transplantation: a 5-year longitudinal study on self-reported quality of life. BMC Nephrol. 2014;15:191.

43. Takahashi A, Hu SL, Bostom A. Physical Activity in Kidney Transplant Recipients: A Review. Am J Kidney Dis. 2018;72(3):433-43.

44. Gordon EJ, Prohaska TR, Gallant M, Siminoff LA. Self-care strategies and barriers among kidney transplant recipients: a qualitative study. Chronic Illn. 2009;5(2):75-91.

45. Lim HJ, Koo TY, Lee J, Huh KH, Park JB, Cho J, et al. Health-Related Quality of Life of Kidney Transplantation Patients: Results from the KoreaN Cohort Study for Outcome in Patients With Kidney Transplantation (KNOW-KT) Study. Transplant Proc. 2016;48(3):844-7.

46. Carr AJ, Gibson B, Robinson PG. Measuring quality of life: Is quality of life determined by expectations or experience? Bmj. 2001;322(7296):1240-3.

47. Valderrábano F, Jofre R, López-Gómez JM. Quality of life in end-stage renal disease patients. Am J Kidney Dis. 2001;38(3):443-64.

48. Oguchi H, Tsujita M, Yazawa M, Kawaguchi T, Hoshino J, Kohzuki M, et al. The efficacy of exercise training in kidney transplant recipients: a meta-analysis and systematic review. Clin Exp Nephrol. 2019;23(2):275-84.

49. Reese PP, Bloom RD, Shults J, Thomasson A, Mussell A, Rosas SE, et al. Functional status and survival after kidney transplantation. Transplantation. 2014;97(2):189-95.

50. Yamagata K, Hoshino J, Sugiyama H, Hanafusa N, Shibagaki Y, Komatsu Y, et al. Clinical practice guideline for renal rehabilitation: systematic reviews and recommendations of exercise therapies in patients with kidney diseases. Renal Replacement Therapy. 2019;5(1):28.

\section{Figures}




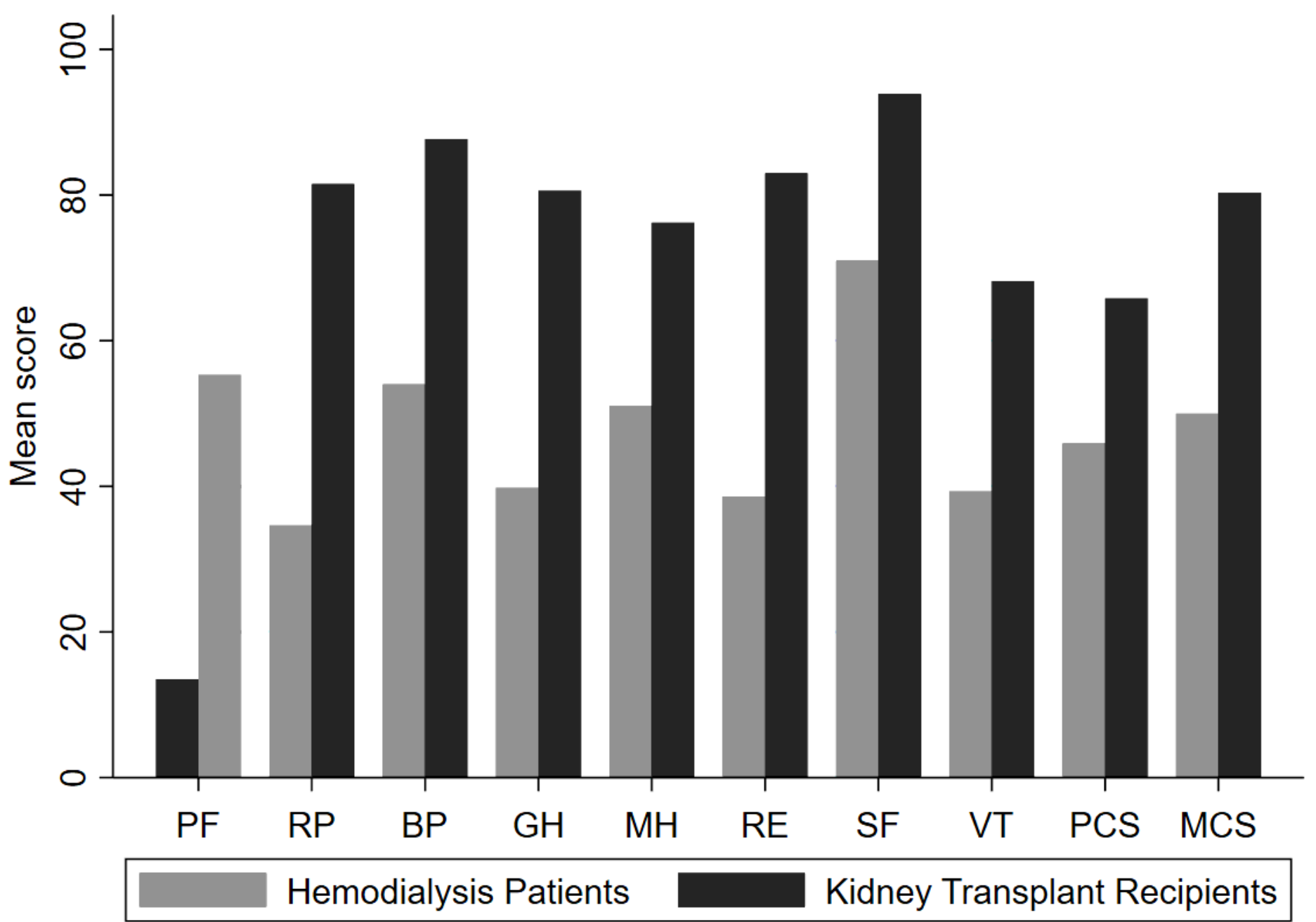

Figure 1

Unadjusted SF-36 mean scores in kidney transplant recipients $(n=100)$ and hemodialysis patients ( $n=272)$ PF, Physical functioning; RP, Role-physical; BP, Bodily pain; GH, General health; VT, Vitality; SF, Social functioning; RE, Role-emotional; MH, Mental health; PCS, Physical component summary; MCS, Mental component summary. 


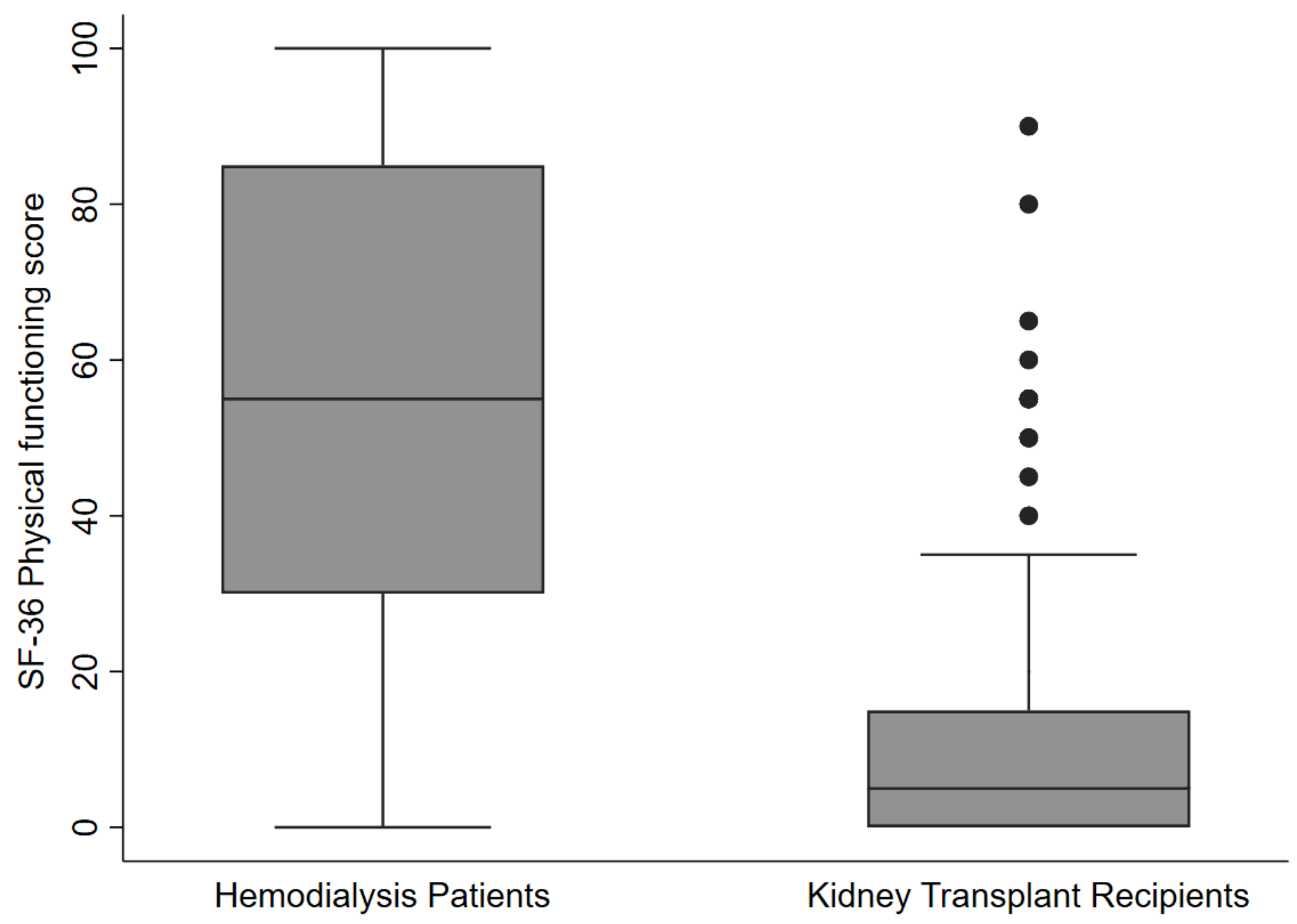

Figure 2

Box plots for health related quality of life in physical functioning scores among kidney transplant recipients $(n=100)$ and hemodialysis patients $(n=272)$ 